\title{
Re: The Utility of Sex Hormone-Binding Globulin in Hypogonadism and Infertile Males
}

Ring J', Welliver $\mathrm{C}^{2}$, Parenteau $\mathrm{M}^{3}$, Markwell S', Brannigan RE ${ }^{4}$, Köhler TS ${ }^{5}$

'Southern Illinois University Faculty of Medicine, Department of Urology, Springfield, USA

${ }^{2}$ Urological Institution of Northeastern New York, Albany, USA

${ }^{3}$ Naval Medical Center San Diego, San Diego, California

${ }^{4}$ Northwestern University Feinberg Faculty of Medicine, Department of Urology, Chicago, USA

${ }^{5}$ Southern Illinois University Faculty of Medicine, Department of Urology, Springfield, USA

J Urol 2017;197:1326-1331. doi: 10.1016/j.juro.2017.01.018.

\section{EDITORIAL COMMENT}

Hypogonadism is defined by both low morning testosterone levels and symptoms of low testosterone. Low testosterone is usually defined as a testosterone level below $300 \mathrm{ng} / \mathrm{dL}$. However, the authors concluded in their cohort that up to $20 \%$ of patients who had a testosterone level of greater than $300 \mathrm{ng} / \mathrm{dL}$ were actually hypogonadal if bioavailable testosterone (BT) was calculated using sex hormone-binding globulin (SHBG). When symptomatic patients with a BT level between 156 and $210 \mathrm{ng} / \mathrm{dL}$ were included, it was observed that up to 53\% of men were hypogonadal although their testosterone levels were normal and they could have benefited from testosterone therapy. It is suggested that in assessing hypogonadism in men, SHBG might have a diagnostic role and SHBG levels independently predict decreased sperm concentration and motility when compared to follicle-stimulating hormone levels.

Emre Bakırcıoğlu, MD 